\title{
Correction to: Identifying energy-inefficient industries vulnerable to trade dependence of energy sources
}

\author{
Dongsuk Kang • Duk Hee Lee
}

Published online: 27 May 2018

(C) Springer Science+Business Media B.V., part of Springer Nature 2018

\section{Correction to: Energy Efficiency https://doi.org/10.1007/s12053-018- 9638-4}

The captions of Figs. 7, 8, and 9 were incorrectly switched during typesetting. The caption of Fig. 7 should have been the caption of Fig. 8. Caption of Fig. 8 should have been the caption of Fig. 9. The caption of Fig. 9 should have been the caption of Fig. 7.

The online version of the original article can be found at https://doi.org/10.1007/s12053-018-9638-4

D. Kang

Future Research Center (FRC), Gwangju Institute of Science and Technology (GIST), 123 Cheomdangwagi-ro, Buk-gu,

Gwangju 61005, Republic of Korea

e-mail: ideartworld@gist.ac.kr

D. Kang

e-mail: paper2black@gmail.com

D. Kang

Advanced Photonics Research Institute (APRI), Gwangju Institute of Science and Technology (GIST), 123 Cheomdangwagi-ro,

Buk-gu, Gwangju 61005, Republic of Korea

\section{H. Lee $(\bowtie)$}

School of Business and Technology Management (BTM), College of Business, Korea Advanced Institute of Science and Technology (KAIST), 291 Daehak-ro Yuseong-gu, Daejeon 305-701, South

Korea

e-mail: dhlnexys@kaist.ac.kr
Fig. 7 Net proportions of industries influenced by the electricity shock per step of shock propagation

Fig. 8 Net proportions of industries influenced by the shock from town gas suspension per step of shock propagation

Fig. 9 Cumulative proportions of industries influenced by energy shocks in terms of propagation steps in 2012 